\title{
Early childhood risk and resilience factors for behavioural and emotional problems in middle childhood
}

\author{
Jason L Cabaj ${ }^{*}$, Sheila W McDonald ${ }^{2}$ and Suzanne C Tough ${ }^{1,2}$
}

\begin{abstract}
Background: Mental disorders in childhood have a considerable health and societal impact but the associated negative consequences may be ameliorated through early identification of risk and protective factors that can guide health promoting and preventive interventions. The objective of this study was to inform health policy and practice through identification of demographic, familial and environmental factors associated with emotional or behavioural problems in middle childhood, and the predictors of resilience in the presence of identified risk factors.

Methods: A cohort of 706 mothers followed from early pregnancy was surveyed at six to eight years post-partum by a mail-out questionnaire, which included questions on demographics, children's health, development, activities, media and technology, family, friends, community, school life, and mother's health.

Results: Although most children do well in middle childhood, of 450 respondents (64\% response rate), $29.5 \%$ and $25.6 \%$ of children were found to have internalising and externalising behaviour problem scores in the lowest quintile on the NSCLY Child Behaviour Scales. Independent predictors for problem behaviours identified through multivariable logistic regression modelling included being male, demographic risk, maternal mental health risk, poor parenting interactions, and low parenting morale. Among children at high risk for behaviour problems, protective factors included high maternal and child self-esteem, good maternal emotional health, adequate social support, good academic performance, and adequate quality parenting time.
\end{abstract}

Conclusions: These findings demonstrate that several individual and social resilience factors can counter the influence of early adversities on the likelihood of developing problem behaviours in middle childhood, thus informing enhanced public health interventions for this understudied life course phase.

\section{Background}

The public health burden of childhood mental and behavioural problems is substantial. The point prevalence of mental disorders in youth has been estimated to be between $10 \%$ and $20 \%$, with even higher rates found in disadvantaged children [1-3]. Further, because childhood behaviour exists on a continuum, many children that do not meet criteria for clinical diagnoses still exhibit maladaptive emotional and behavioural traits that have a substantial influence on long-term outcomes in multiple domains, including academic achievement, health, and social and economic success [4]. Notably, the origins of

\footnotetext{
*Correspondence: Jason.Cabaj@albertahealthservices.ca

'Department of Community Health Sciences, University of Calgary, Calgary,

Alberta, Canada

Full list of author information is available at the end of the article
}

mental illnesses that persist throughout the lifecycle often have their origins in childhood, manifesting as both internalizing and externalizing behaviours. In Canada, although mental health spending is lower than in most developed countries, more than \$14 billion in government expenditures went towards mental health in 2010 [5]. When health related quality-of-life losses are considered, the economic burden of mental disorders in Canada has been estimated to exceed $\$ 50$ billion per year [6].

A growing body of research suggests that developmental trajectories resulting in poor health outcomes are established early in life and are predicted by numerous prenatal, perinatal, and childhood factors that reflect environmental adversity [7-9]. Exposure to misfortune in early childhood has been shown to increase the odds of 
poor mental health and problem behaviours that persist into adolescence and adulthood, such as antisocial tendencies, substance abuse, mood disorders, and suicide attempts [10-13]. In some cases, a dose response relationship between the number of adverse childhood events experienced and later mental health problems has been demonstrated [14].

Because few young people are entirely free from risk, and the existing options for treatment of children and adolescents diagnosed with mental disorders remain limited, the further development of effective preventive approaches would have enormous potential benefits $[15,16]$. Thus, as Waddel et al. and others have noted, determination of both the risk factors associated with mental disorders, and the protective factors which may either lower the likelihood or reduce the negative impact of these outcomes, is necessary to inform the planning and implementation of preventive and health promoting interventions $[17,18]$. Modifiable protective factors that have been identified in previous research include parenting practices and levels of confidence, social support, and maternal mental health [19-22].

This paper describes the most recent study arising from a cohort of mothers and children in Calgary, an urban centre in Alberta, Canada, that have been followed since the perinatal period and surveyed periodically (at three, five, and now eight years of age). The first Community Perinatal Care Study, a randomized controlled trial (RCT) of three types of prenatal care, found that additional prenatal support from nurses and home visitors increased the use of community based resources and access to pregnancyrelated information, but did not alter alcohol/tobacco use, post-partum depression, or birth outcomes [23]. A followup survey at three years of age reported that $11 \%$ of this demographically low-risk (by maternal education and family income) sample of Canadian children screened at high risk for developmental problems, with poor maternal mental health identified as the strongest predictor of a positive screen. [24]. Subsequently, follow-up of the cohort at age five identified maternal well-being and history of abuse as primary risk factors for developmental problems, and documented the persistent influence of maternal influences on infant and child development up to school entry [25].

The third Community Perinatal Care (CPC-8) follow-up study, called "It's All about Me! Middle Childhood Survey", was designed to explore family, school and community life of children through a questionnaire distributed in middle childhood. The objectives of the present study were to use CPC- 8 data to identify the combination of current and past demographic, familial and environmental factors associated with emotional or behavioural problems in middle childhood, and the predictors of resilience in the presence of previously identified risk factors for delayed development. We hypothesized that adversity in early and middle childhood would be associated an increased risk of internalizing and externalizing behaviours, but that enhanced social and emotional well-being could provide protection against poor mental health outcomes.

\section{Methods \\ Participants}

The participants in this study are part of the longitudinal Community Perinatal Care (CPC) cohort that had been followed since pregnancy [23]. The initial sample for the CPC study included pregnant women over 18 years of age who attended one of three family physician low-risk maternity practices in the Calgary Health Region. Mothers who agreed to participate beyond the randomized controlled trial were surveyed as part of the first follow up study (CPC-3) when their children were three years old $(\mathrm{n}=791)$. Subsequently, when the children were aged four to six years and six to eight years respectively, participants from the $\mathrm{CPC}-3$ study that indicated willingness to participate in future research formed the cohorts for both the second (CPC-5) and third (CPC-8) follow-up studies. Exclusion criteria consisted of the inability to complete the questionnaire in English and lack of current mailing information after exhaustive searching. Findings from the original CPC study and the first two follow-up studies are reported elsewhere [23-25].

\section{Questionnaire}

The CPC-8 survey (consisting of a 21-page questionnaire) included questions on demographics, children's health, development, activities, media and technology, family, friends, community, school life, and mother's health (see Additional file 1). The questionnaire was revised based on pilot testing with a small sample of mothers $(n=13)$ for length, flow, comprehension, and response burden, and took about 20-25 minutes to complete.

Postcards outlining plans for another CPC follow-up study were mailed to the last known address of the 706 respondents from the CPC-3 study in the summer of 2009. Research assistants then used Facebook, directory assistance, and study database phone numbers to contact respondents whose postcards had been returned-to-sender. In January 2010, the CPC-8 questionnaire was sent to these mothers along with a cover letter informing participants of the voluntary nature of their participation, confidentiality of their information, and a description of potential linkages with previously collected data. Mothers also received a postage-paid envelope, and a one-time recreation pass (in appreciation of their time and contribution to the study). The methods described above were again used by research assistants to obtain updated addresses when study questionnaires were returned-to-sender.

Reminder phone calls were made at one and two months after the survey mail-out to mothers with outstanding 
questionnaires, and letters were sent at 3 months to women who could not be contacted by phone reminding them of the study and requesting they call study investigators if they required another copy of the questionnaire. A second copy of the questionnaire was sent to women who had expressed a commitment to return the questionnaire and to those who research assistants had not been able to speak with on the phone. Finally, further phone calls were made to mothers with outstanding questionnaires that had received a second copy and/or had expressed intent to complete the questionnaire. Data collection and follow-up ended in June 2010. Questionnaires were scanned to an Access database after verification with Teleform, an electronic data capture and management system [26]. Ethics approval was granted to the study from the Conjoint Health Research Ethics Board at the University of Calgary.

\section{Variables}

Study variables, including dependent and independent variables, were drawn from all data collection time points for the CPC cohort. Both single item investigator derived questions and standardized instruments were used.

\section{Outcome measures}

Study outcome variables were problem behaviours, a classification intended to capture a range of perceived difficulties in children and adolescents (i.e. medical, biological, and psychological conditions). The specific outcomes assessed were the presence of externalizing behaviours, in which psychosocial maladjustment is manifested outwardly (e.g. hyperactivity, aggression, or violence), and internalizing behaviours, in which distress is manifested in an inhibited style of social interaction (e.g. such as anxiety or depression). Outcomes were measured using the National Longitudinal Survey of Children and Youth (NLSCY) Child Behavioural Scales [27], which were derived from a pool of items from previous studies and underwent psychometric testing to ensure validity with DSM-IV criteria [28]. Scales that assessed externalizing and internalizing behaviours were combined to produce externalizing and internalizing dimensions, respectively. For subscales that composed the externalizing dimension, Chronbach's alpha reliability coefficient ranged from $0.77-0.84$. The reliability coefficient for the internalizing scale was 0.79 . For each dimension, scores at or above the 80th percentile of the distribution were used to classify children as manifesting problem behaviours, consistent with prior studies using these scales [29].

\section{Independent variables}

Predictor variables fell into three groups: demographic factors, child characteristics, and maternal characteristics.

\section{Demographic factors}

Demographic information based on maternal self-report collected in CPC studies included marital status, education, annual household income, ethnicity, and household composition. Indicator variables to capture demographic risk were derived for both age three (at least one of: single marital status, less than 25 years old, less than a high school education, household income less than $\$ 40,000$, or moved two or more times in the past two years), and age eight (at least one of: single marital status; household income less than $\$ 40,000$; not enough money for food and daily living expenses in the past 3 months; visited food bank in the past 3 months; or not able to pay all of their bills in the past 3 months).

Although we strove for consistency in defining demographic risk, the definition of historical and current demographic risk changed slightly across time due to the availability and relevancy of the variables collected at each time point. For example, young maternal age was included in history of demographic risk but was no longer relevant when the child approached age 8 . Despite this, our demographic risk variables captured constructs of socioeconomic status and indicators of vulnerability (residential stability and food insecurity) at each time point.

\section{Child characteristics}

Child gender, health status, body mass index, history of specialist referral, school performance, and history of stressful or traumatic childhood events were collected based on maternal report in CPC-8. Information from the Parents' Evaluation of Developmental Status (PEDS) standardized measurement scale collected in CPC-3 and CPC-5 follow-up studies was used to determine risk of developmental disability [30].

\section{Maternal characteristics}

Information on maternal physical and emotional health status, (excellent, good, fair, poor, or terrible) [31], history of abuse (any abuse prior to pregnancy), and adequacy of social support were based on self-report data collected during pregnancy, at age three, and at age eight. Information about parenting collected included parenting morale, assessed using the Parenting Morale Index [32] at 3 years post-birth, and parenting style, which was assessed using two subscales of the National Longitudinal Survey of Children and Youth (hostile/ineffective and aversion) [33] at the middle childhood follow-up.

Maternal mental health risk indicators were developed to describe risk during pregnancy (at least one of: abuse prior to pregnancy or up to 6-8 weeks postpartum, depression prior to pregnancy, suicidal thoughts prior to pregnancy, poor social support in first trimester, poor network orientation in first trimester, or poor emotional 
health in first trimester), at age three (at least one of: experience of abuse since child was born, depression for six or more months after giving birth, poor social support, or poor emotional health), and age eight (at least one of: low social support, poor emotional health, or unstable spouse/partner events in the past 12 months).

\section{Analysis}

Data collected in the CPC-8 questionnaire was linked to that from the original CPC study as well as to the previous follow up studies through unique study identification numbers. Data were analysed using the statistical package SPSS (v.19). Data analysis included descriptive methods for categorical and continuous variables as well as bivariate and multivariable methods. For continuous predictors and predictor variables with greater than two levels, dichotomization was carried out for ease of interpretation based on the theoretically most meaningful categories and consistent with previous work using CPC data $[24,25]$. For each outcome, we identified at least 5 variables from each previous and current time point that were significant at $\mathrm{p}<0.01$ in bivariate analysis. This provided a range of both previous and current risk factors covering child and maternal domains for inclusion in the multivariable analysis.

We developed a predictive model for each behavioural dimension using a manual stepwise model building approach that considered current (age 8) risk factors in the first block, followed by incorporation of previous risk factors (age 3 and age 5), to produce a final, parsimonious model. This approach allowed for the assessment of the independent effects of current influences while accounting for risk factors that occurred earlier in childhood. Predictor variables were included in the regression models if they were significantly associated with the outcome in bivariate analysis (using Chi Square or Fisher's exact test) at $\mathrm{p} \leq 0.01$, or there was theoretical rationale (i.e. gender and demographic risk were included in the models regardless of significance of the association with the outcome variables).

To assess resilience in the presence of previously identified risk, a subsample of mothers was selected from the broad study population based on having either demographic or mental health risk (as defined above) when their child was three years old. In order to compare those at the highest risk to those at the lowest risk of problem behaviours, the internalizing and externalizing behaviour scores were categorized at the 'extremes' to capture children who scored either high (80th percentile and above) or low (20th percentile and below) for each dimension. Chi square analysis was carried out to assess the influence of potential protective factors that discriminated children scoring in the low vs. high externalizing or internalizing behaviour categories.

\section{Results}

\section{Demographics}

Of the 706 eligible participants, 450 returned the questionnaires, leading to a $64 \%$ response rate (Figure 1). The majority of mothers who participated in the study were white/Caucasian (87.6\%), married (93.6\%), had completed a post-secondary education (74.2\%), and had a household income of at least $\$ 60,000$ (88.4\%) (Table 1). The average age of these women was 38.4 years $(\mathrm{SD}=$ 4.48 ) and $66.2 \%$ reported that one or two children lived in the household. Twelve percent of mothers reported having a history of demographic risk at age three, while at age eight, approximately one-quarter of the sample reported demographic risk.

\section{Child and maternal characteristics}

The children in the study were evenly distributed based on gender $(48.7 \%$ male), with $5.0 \%$ being preterm infants. The majority of mothers reported their children having above average general health (98.2\%), a healthy BMI (74.1\%), and no health problems as told by a health professional (61.8\%) at age 8. According to maternal self-report for child behaviour, $29.5 \%$ and $25.6 \%$ of children were found to have internalising and externalising behaviour problem scores, respectively, in the lowest quintile of the distribution on the NSCLY Child Behaviour Scales. At either age 3 or 5, 21.8\% of children had screened at high risk of developmental disabilities (Path A) according to the Parents' Evaluation of Development, and $27.3 \%$ of children had a history of referral for any developmental or behavioural concern.

Nearly half of the mothers reported a history of mental health risk during pregnancy $(46.9 \%)$. When their children were three years of age, mental health risk was observed in $18.0 \%$ of the sample, while mental health risk at age eight was seen in $31.2 \%$ of mothers. The different proportions seen according to timing of assessment can be attributed to the different elements that are included in each definition of 'risk', and are largely a reflection of questions asked at the different time points. This is important to keep in mind when interpreting these results, as mental health risk is differentially defined across time. The majority of mothers reported positive parenting interaction with their children (71.6\%), adequate social support (89.3\%), and above average emotional health (84.9\%) when their children were 8.

\section{Key factors associated with internalizing and externalizing behaviours}

Observed risk factors for internalizing behaviour problems at age eight included being male (OR: 1.70; 95\% CI: 1.02, 2.82), previous demographic risk at age 3 (OR: 2.82; 95\% CI: 1.27, 6.26), current maternal mental health risk (OR: 1.96; 95\% CI: 1.15, 3.36), current low positive 


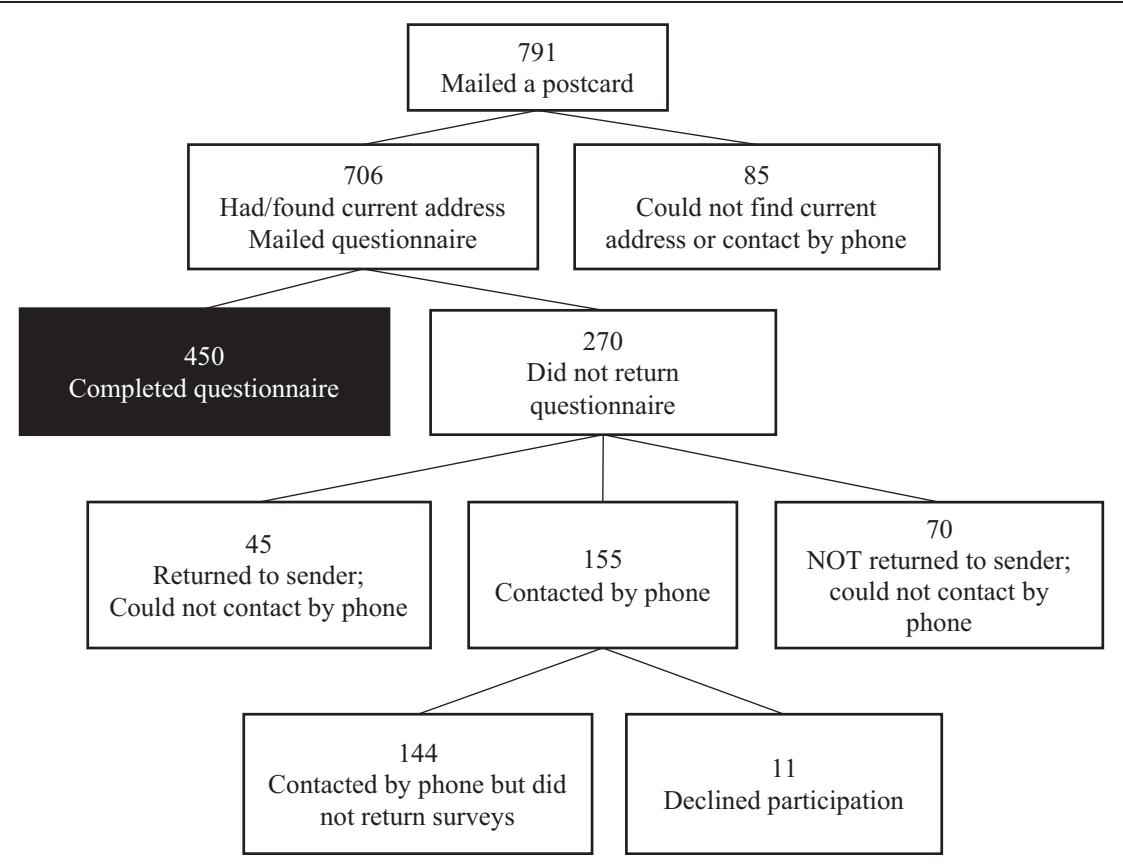

Figure 1 Flowchart of eligibility, recruitment, and completion of mothers who participated in the CPC-8 follow-up study.

parenting interaction (OR: 1.92; 95\% CI: 1.12, 3.30), and previous low parenting morale (OR: 2.62; 95\% CI: 1.43, 4.82) (Table 2).

For externalizing behaviours, being male (OR: 2.64; 95\% CI: $1.50,4.65)$, previous maternal mental health risk at age 3 (OR: 2.02; 95\% CI: 1.02, 4.01), previous hostile parenting at age 3 (OR: 2.24; 95\% CI: 1.12, 4.50), previous low satisfaction in parenting sense of competence at age 5 (OR: 2.83; 95\% CI: 1.58, 5.06), previous referral for developmental or behavioural concerns at age 3 (OR: 1.99; 95\% CI: 1.04, 3.83), any unhappy childhood event (OR: 2.14 ; 95\% CI: 1.09, 4.19), and current poor to average school performance (OR: 2.07; 95\% CI: 1.16, 3.69) were independent risk factors (Table 2).

\section{Factors related to positive outcomes in the presence of previous risk}

Among mothers with previously identified demographic or mental health risk when their child was 3 years old ( $\mathrm{n}=111$ ) [24], a low degree of internalizing behaviours in the child was associated with high overall self-esteem at age 8 as reported by the mother ( 89.5 vs. $63.3 \%$; $\mathrm{p}=0.033$ ). Child factors associated with a low degree of externalizing behaviours included mothers report that their 8-year old child had two or more close friends (93.8 vs. $72.1 \%$; $\mathrm{p}=0.017$ ), high overall self-esteem $(87.5$ vs. $65.1 \% ; \mathrm{p}=0.027$ ), good school performance (75.0 vs. $51.2 \% ; \mathrm{p}=0.036)$, and high social competence at age 5 ( 40.0 vs. $6.1 \% ; p=0.004)$. Maternal factors associated with a low degree of externalizing behaviours included current high social support (40.6 vs. 9.3\%; $\mathrm{p}=0.001$ ), very good emotional health (50.0 vs. $25.6 \%$; $\mathrm{p}=0.029$ ), and adequate good quality time spent with their child (ren) (78.1 vs. 46.5\%; $\mathrm{p}=0.006$ ) (Table 3).

\section{Discussion}

The findings of the present study confirm the importance of several recognized individual, family, and social factors in predicting the development of emotional and behavioural disorders [34], and build upon the results of the previous CPC follow-up studies at three and five years by demonstrating the persistent influence of early childhood adversity on developmental outcomes into the middle childhood years $[24,25]$. Broadly, the CPC research findings demonstrate the vital importance of maternal well-being and parent-child relationships on healthy development, particularly in the early years.

Although over $98 \%$ of children were reported to be in good to excellent general health, and despite the relatively high affluence of this sample of middle and upper income families with access to publicly funded universal health care, a substantial proportion of children (greater than $25 \%$ for each of the behaviour outcomes) were reported to exhibit problematic behaviours. These results highlight that the factors associated with an increased risk of behavioural disorders in children are not limited to conventional measures of socioeconomic status, as the largest number of vulnerable children reside in the middle class [14]. Further, because the emotional and behavioural problems identified in children and adolescents are dependent on 


\section{Table 1 Characteristics of mothers and children who participated in the CPC-8 study

\begin{tabular}{lc}
\hline Characteristic & $\begin{array}{c}\text { Total sample } \\
(\mathrm{N}=450) \mathrm{n}(\%)\end{array}$ \\
\hline
\end{tabular}

\section{Demographics}

Maternal age*

Mean (SD)

$38.42(4.478)$

Marital status*

Married/common-law

$421(93.6)$

Single, divorced, or separated

$29(6.4)$

Education*

Completed post-secondary

Less than post-secondary

Household income*

Less than $\$ 60,000$

$\$ 60,000$ or more

Ethnicity**

White/Caucasian

Other

Number of children in household*

One to two children

Three or more children

History of demographic risk: less than 25 years old, less than $\$ 40,000$ income, single, high school education or less, or moved 2 or more times in the past 2 years**

Yes

No

$55(12.2)$

$395(87.8)$

Current demographic risk: less than $\$ 40,000$ income, single, or food/expense instability*

$$
\begin{aligned}
& \text { Yes } \\
& \text { No }
\end{aligned}
$$

\section{Child Characteristics}

Gender**

$$
\text { Girl }
$$

Boy

$228(52.2)$

$209(47.8)$

Preterm infant**

$$
\text { Yes }
$$

No

$414(95.0)$

General health*

Excellent, very good, or good

$441(98.2)$

Fair or poor

BMI status*

Underweight

Healthy

$297(74.1)$

$65(16.2)$
Table 1 Characteristics of mothers and children who participated in the CPC-8 study (Continued)

Number of health problems as told by health professional*

$$
\begin{aligned}
& \text { No health problems } \\
& \text { At least one health problem }
\end{aligned}
$$

$172(38.2)$

High externalizing behaviour (scored $\geq 80^{\text {th }}$ percentile)*

Yes

$114(25.6)$

No

$332(74.4)$

High internalizing behaviour (scored $\geq 80^{\text {th }}$ percentile)*

$$
\text { Yes }
$$

No

$315(70.5)$

Low prosocial behaviour (scored $\leq 20^{\text {th }}$ percentile) ${ }^{*}$

Yes

$116(25.9)$

No

$332(74.1)$

Referral to at least one of early intervention program, speech or language pathologist, developmental pediatrician, psychologist, physiotherapist, or dietician at 3 years or 5 years**

Yes

$123(27.3)$

No

$327(72.7)$

PEDS Path $A$ at 3 years or 5 years of age**

Yes

$83(21.8)$

No

$297(78.2)$

\section{Maternal Characteristics}

History of mental health risk: abuse (prior to pregnancy, during pregnancy, 6-8 weeks postpartum), depression (prior to pregnancy), suicide (prior to pregnancy), poor social support (first trimester), poor network orientation (first trimester), poor emotional health (first trimester)**

$\begin{array}{ll}\text { Yes } & 211(46.9) \\ \text { No } & 239(53.1)\end{array}$

Mental health risk at CPC3Year: abuse, depression (6+ months postpartum), poor social support, poor emotional health**

Yes

$81(18.0)$

No

$369(82.0)$

Current mental health risk: low social support, poor emotional health, or unstable spouse/partner events in the past 12 months* $^{*}$

$\begin{array}{ll}\text { Yes } & 138(31.2) \\ \text { No } & 305(68.8)\end{array}$

Low positive parenting interaction (scored $\leq 20^{\text {th }}$ percentile)*

Yes

$128(28.4)$

No

$322(71.6)$

Low social support (scored $<15^{\text {th }}$ percentile)*

Yes 


\section{Table 1 Characteristics of mothers and children who participated in the CPC-8 study (Continued)}

\begin{tabular}{lc}
\hline Emotional health in past 6 months* & $382(84.9)$ \\
Excellent, very good, or good & $68(15.1)$ \\
Fair or poor & \\
Unstable events that occurred during the past & \\
12 months to mother or spouse/partner* & $370(83.5)$ \\
None to two events & $73(16.5)$ \\
Three or more events
\end{tabular}

*variable assessed at current (middle childhood) assessment time point. **variable assessed at previous time points.

the role of the reporting adult in their life, many problems may go undetected even by parents, suggesting that the occurrence of the problem behaviours reported here is likely an underestimate, particularly for internalizing behaviours $[35,36]$. An unexpected finding of the study was that the risk of both externalizing and internalizing behaviours was higher for males, a pattern not typically seen in previous research.

These results are consistent with previous research demonstrating strong relationships between early life events and internalizing and externalizing behaviours in adolescents and young adults $[37,38]$. Paramount among the significant factors in this study were indicators of maternal emotional and social well-being, including current and past maternal mental health risk, and several measures characterizing different facets of parenting difficulty. Notably, past maternal mental health risk, which captured distress in the prenatal and early postpartum periods, and has been linked to a reduced quality of parent-child relations [39], was associated with twice the risk of developing externalizing behaviours $(31 \%$ vs. $14 \%$ in those with and without externalizing behaviours, respectively). Similarly, the majority of parenting difficulties measures reported on here (low positive parenting interactions, low parenting morale, low parenting sense of competence, and hostile parenting) were obtained at age 3 or 5 in the previous CPC follow-up studies. Thus, these findings denote the substantive continued influence of early parenting quality and maternal well-being into middle childhood and point to the potential value of timely intervention. Furthermore, it is interesting to note that different parenting variables were independently predictive of child behaviour outcomes, which suggests that they were measuring different aspects of the parenting environment, from parenting style to feelings of confidence.

Various models of resilience, or the ability to develop successfully in spite of adversity and environmental challenges, have been proposed to explain how risk and protective factors interact $[40,41]$. Resilience information is especially pertinent for preventive efforts, as recent evidence suggests that interventions enhancing protective factors may be more effective than those aimed at reducing risk of poor child outcomes [42]. Our research illustrates that certain child and maternal factors have a discernible protective effect against the development of problem behaviours, particularly those manifesting externally. Multiple resilience factors identified in the present study (high child self-esteem and social competence, high maternal social support and emotional health) are cogently related to adequate social support and connectedness, constructs which have been proposed to serve as a moderators between stressful events and poor mental health outcomes (including internalizing and externalizing behaviours) [43].

A sensitivity analysis that incorporated the middle range of scores on the behaviour scale into the low risk category was carried out, and the results with respect to protective factors were unchanged (data not shown). Of note, the cut-off used in the present study was based on the sample distribution of scores and the majority of children scored in the low range on both outcomes. Therefore, further examination of more stringent cut-offs are warranted, as are other approaches such as examination of interactions using the full sample in larger studies with both continuous and categorical outcomes.

Effective public health policies to prevent mental disorders and promote mental health "should encompass multiple preventive interventions addressing multiple causal trajectories for the relevant populations at risk" $[16,44]$, demonstrating the need for both universal and targeted strategies. Because the demographic and social risks seen in this cohort are pervasive throughout social strata, programs which focus exclusively on low socioeconomic status or specific risk factors will miss a large number of children and families who are affected by adverse childhood experiences [14]. For example, although less than $5 \%$ of women reported household incomes of $<\$ 40,000$ year, a large portion of the greater demographic risk observed at age eight was still related to food and/or income insecurity, with over $10 \%$ of mothers lacking adequate money for paying bills, obtaining food, or daily living expenses. Thus, our results support the assertion that to broadly develop resilience in the population, strategies for optimizing child development should begin early in life and should foster social support, resource management and coping strategies, and engagement with others and the community, regardless of socioeconomic status.

Although comprehensive identification of children and families that would benefit from targeted interventions remains a challenge, historically many of the most successful early life programs have been aimed at at-risk child populations [45]. Our results suggest that the early detection of 
Table 2 Key risk factors for problem behaviours at age eight

\begin{tabular}{|c|c|c|c|c|}
\hline \multirow[t]{2}{*}{ Variable } & \multicolumn{2}{|c|}{ Externalizing behaviours } & \multicolumn{2}{|c|}{ Internalizing behaviours } \\
\hline & Adjusted odds ratio (95\% C.I.) & p-value & Adjusted odds ratio (95\% C.I.) & p-value \\
\hline Male gender & $2.64(1.50,4.65)$ & 0.001 & $1.70(1.02,2.82)$ & 0.042 \\
\hline Current demographic risk & $1.63(0.86,3.10)$ & 0.134 & & \\
\hline Past demographic risk & & & $2.82(1.27,6.26)$ & 0.011 \\
\hline Current maternal mental health risk & & & $1.96(1.15,3.36)$ & 0.014 \\
\hline Past maternal mental health risk & $2.02(1.02,4.01)$ & 0.044 & & \\
\hline Absence of positive parenting interactions & & & $1.92(1.12,3.30)$ & 0.017 \\
\hline Past low parental sense of competence & $2.83(1.58,5.06)$ & $<0.001$ & & \\
\hline Past hostile parenting style & $2.24(1.12,4.50)$ & 0.023 & & \\
\hline Past low parenting morale & & & $2.62(1.43,4.82)$ & 0.002 \\
\hline Past unhappy events for child & $2.14(1.09,4.19)$ & 0.027 & & \\
\hline Developmental referral history & $1.99(1.04,3.83)$ & 0.039 & & \\
\hline Poor school performance & $2.07(1.16,3.69)$ & 0.014 & & \\
\hline
\end{tabular}

Note. Internalizing and externalizing behaviours defined by behaviour scales previously used in the Ontario Child Health Study (OCHS) with the cut-offs made at the 80 th percentile (coding: Less than 80 th percentile vs. 80th percentile or better).

Table 3 Protective factors from problem behaviours in the presence of previous risk

\begin{tabular}{|c|c|c|c|c|c|c|}
\hline & \multicolumn{3}{|c|}{ Internalizing behaviours } & \multicolumn{3}{|c|}{ Externalizing behaviours } \\
\hline & $\begin{array}{l}\text { Low degree } \\
(\leq 20 \text { th })\end{array}$ & $\begin{array}{l}\text { High degree } \\
\text { ( } \geq 80 \text { th })\end{array}$ & & $\begin{array}{l}\text { Low degree } \\
\text { ( } \leq 20 \text { th })\end{array}$ & $\begin{array}{l}\text { High degree } \\
(\geq 80 \mathrm{th})\end{array}$ & \\
\hline & $\mathrm{N}=19$ & $\mathrm{~N}=50$ & p-value & $\mathrm{N}=32$ & $\mathrm{~N}=43$ & p-value \\
\hline Characteristics & n (\%) & n (\%) & & n (\%) & n (\%) & \\
\hline Attends sporting events, art/cultural events, camping events & $16(84.2)$ & $42(85.7)$ & 1 & $30(93.8)$ & $37(86.0)$ & 0.454 \\
\hline Spends time participating in activities & $14(77.8)$ & $37(74.0)$ & 1 & $27(87.1)$ & $33(76.7)$ & 0.262 \\
\hline Low screen time - weekdays & $12(63.2)$ & $29(59.2)$ & 0.764 & $22(68.8)$ & $21(50.0)$ & 0.105 \\
\hline Low screen time - weekends & $4(21.1)$ & $7(14.3)$ & 0.486 & $7(21.9)$ & $6(14.3)$ & 0.395 \\
\hline Spends two or more days with friends outside of school & $10(52.6)$ & $27(54.0)$ & 0.919 & $18(56.3)$ & $21(48.8)$ & 0.525 \\
\hline Two or more close friends & $18(94.7)$ & $39(78.0)$ & 0.157 & $30(93.8)$ & $31(72.1)$ & 0.017 \\
\hline High maternal social support & $4(22.2)$ & $7(14.0)$ & 0.464 & $13(40.6)$ & $4(9.3)$ & 0.001 \\
\hline High positive parenting interaction & $5(26.3)$ & $8(16.0)$ & 0.326 & $8(25.0)$ & $5(11.6)$ & 0.13 \\
\hline High neighbourhood cohesion & $1(5.6)$ & $5(11.1)$ & 0.664 & $8(25.0)$ & $3(7.5)$ & 0.052 \\
\hline At least 1 community involvement event & $18(94.7)$ & $48(96.0)$ & 1 & $32(100.0)$ & $41(95.3)$ & 0.504 \\
\hline At least 1 school involvement event & $17(89.5)$ & $39(78.0)$ & 0.491 & $28(87.5)$ & $37(86.0)$ & 1 \\
\hline Excellent or very good general health - child & $18(94.7)$ & $41(82.0)$ & 0.264 & $29(90.6)$ & $37(86.0)$ & 0.724 \\
\hline High self-esteem - child & $17(89.5)$ & $31(63.3)$ & 0.033 & $28(87.5)$ & $28(65.1)$ & 0.027 \\
\hline Well/Nery well school performance & $12(63.2)$ & $28(56.0)$ & 0.591 & $24(75.0)$ & $22(51.2)$ & 0.036 \\
\hline Excellent or very good emotional health - maternal & $6(31.6)$ & $13(26.0)$ & 0.643 & $16(50.0)$ & $11(25.6)$ & 0.029 \\
\hline Quality time spent with children & $12(63.2)$ & $29(58.0)$ & 0.697 & $25(78.1)$ & $20(46.5)$ & 0.006 \\
\hline High parenting sense of competence - efficacy & $3(20.0)$ & $4(11.4)$ & 0.415 & $5(25.0)$ & $3(9.4)$ & 0.235 \\
\hline High parenting sense of competence - satisfaction & $2(13.3)$ & $8(22.9)$ & 0.702 & $6(30.0)$ & $7(21.2)$ & 0.522 \\
\hline High child social competence & $5(33.3)$ & $4(11.4)$ & 0.106 & $8(40.0)$ & $2(6.1)$ & 0.004 \\
\hline High parenting morale - 5 years & $2(13.3)$ & $4(11.4)$ & 1 & $6(30.0)$ & $3(9.1)$ & 0.067 \\
\hline High maternal social support - 5 years & $3(20.0)$ & $2(5.9)$ & 0.16 & $4(21.1)$ & $2(6.1)$ & 0.175 \\
\hline
\end{tabular}


mothers with parenting difficulties or a history of poor mental health, followed by provision of support that addresses sense of competence, morale, and parenting strategies, could lead to positive impacts on parental wellbeing and child mental and behavioural outcomes. Identification of mothers with punitive parenting styles and assistance with transitions to more supportive parenting have been associated with improvements in social and behavioural development and have been shown to buffer the effects of early adversities [46]. Development of personal skills that facilitate caring relationships are especially important for those with adverse life experiences as they may have more limited parenting knowledge, a point amplified because of the intergenerational persistence of parenting difficulties [47]. Similarly, interventions to develop better partner communication may reduce tension in relationships, leading to improved parenting competencies and reduced child maladjustment [48]. Such approaches would likely also capture those at risk of developmental problems [24], demonstrating the benefit of upstream approaches addressing this fundamental determinant of health.

Several limitations should be considered when interpreting the results of the present study. First, the sample for the CPC study was drawn from a population of women who received routine prenatal care in low risk maternity clinics. The relatively high level of education and income in this group potentially raises concerns about the generalizability of study results to those of lower socioeconomic status and to marginalized groups. Nevertheless, in earlier CPC follow-up studies it was found that $15 \%$ of children screened at highest risk for developmental problems, a proportion in line with expectations for a population-based setting and the risk and protective factors identified in this study cut across the socioeconomic spectrum. Additionally, the authors recognize that the absence of data on fathers in this study and many others regrettably perpetuates the substantial bias toward mother-child interactions that exists in the parenting literature. Further research that involves risk and resilience factors as they pertain to fathers is needed.

The original CPC study was a community-based study that was not initially designed for longitudinal follow-up, and traditional strategies to retain women were not immediately implemented. Women who were younger, had lower education and income, and were in poor physical health, were single or divorced, and who smoked were less likely to be represented in the follow-up CPC surveys [49]. These factors are similar to the characteristics of women who are generally difficult to retain in longitudinal research [50]. Retention strategies were implemented between the follow-up study at three, five, and eight years (e.g. routine contact, asking women to provide change in contact information). In all three studies, the participation rates were over $60 \%$, and the women not retained in the cohort appear to be similar over the follow-up period. However, the potential for selection bias does exist given attrition of lower SES women across time (data not shown). If the demographic factors related to a lower likelihood of study participation adversely influenced child outcomes, this data will have underestimated the proportion of children with emotional and behavioural disorders. Therefore, our results are generalizable to populations sharing characteristics of the sample in the present study.

The dichotomous classification used in this study (internalizing/externalizing behaviours) is simplistic and does not capture all emotional and behavioural problems in children, but these two dimensions are most commonly used in research settings. The associations between parental wellbeing and the development of behavioural disorders in children are likely bidirectional, as the presence of emotional and behaviour problems in children may be a stressor for mothers and fathers, with subsequent influence on their mental health [51]. As well, although study outcomes were considered in isolation, this is an artificial distinction as children with externalizing disorders may have cooccurring internalizing disorders [52]. This category of children, as defined by scores at or above the 80th percentile for both internalizing and externalizing behaviours, composed $11 \%$ (51/444) of our study population. Similarly, the resilience factors identified reflect associations only, and due to the timing of assessment for some, we cannot preclude the possibility that the protective factors were manifestations of good mental health. Finally, because the study results were based on questionnaires, parents may have underestimated behavioural problems in their children, and it is not possible to determine if the children in whom parents reported problems have any psychiatric disorders, limiting assessment of the severity of health outcomes.

\section{Conclusions}

Middle childhood problem behaviours were common in this sample of conventionally low-risk families. Adversity in critical periods of development was associated with internalizing and externalizing behaviours. However, individual and social resilience factors were shown to counter the influence of early misfortune on the likelihood of developing problem behaviours in middle childhood. Effective universal and targeted strategies to prevent mental disorders and promote mental health thus have the potential to produce substantial lifetime benefits in multiple wellness domains.

\section{Consent}

Written informed consent was obtained from the patient's guardian/parent/next of kin for the publication of this report and any accompanying images. 


\section{Additional file}

\section{Additional file 1: CPC 8 Questionnaire. CPC-8 follow-up study} questionnaire.

\section{Competing interests}

The authors declare that they have no competing interests.

\section{Authors' contributions}

The study authors jointly conceived of and designed the study. JLC contributed to the interpretation of data and drafted the manuscript. SWM carried out the analysis of the data, contributed to the interpretation of data, and revised the manuscript for important intellectual content. SCT contributed to the interpretation of data and revised the manuscript for important intellectual content. All authors read and approved the final manuscript.

\section{Acknowledgements}

We would like to thank the UpStart (formerly the Calgary Children's Initiative) of United Way of Calgary and Area for funding the study and for its commitment to research into the wellbeing of all children. We thank the families who participated in the follow-up studies who continue to kindly give their time to complete the questionnaires. As well, we thank Muci Wu for her vital contributions to data reduction and analysis, and Dr. David Strong and Dr. Richard Musto for their helpful suggestions and support for the project.

\section{Author details}

${ }^{1}$ Department of Community Health Sciences, University of Calgary, Calgary, Alberta, Canada. ${ }^{2}$ Department of Pediatrics, University of Calgary, Calgary, Alberta, Canada

Received: 5 November 2013 Accepted: 25 June 2014 Published: 1 July 2014

\section{References}

1. Jaffee SR, Harrington $H$, Cohen P, Moffitt TE: Cumulative prevalence of psychiatric disorder in youths. J Am Acad Child Adolesc Psychiatry 2005, 44(5):406-407.

2. Waddell C, Offord DR, Shepherd CA, Hua JM, McEwan K: Child psychiatric epidemiology and Canadian public policy-making: the state of the science and the art of the possible. Can J Psychiatry 2002, 47(9):825-832.

3. Belfer ML: Child and adolescent mental disorders: the magnitude across the globe. J Child Psychol Psychiatry 2008, 49(3):226-236.

4. Hertzman C, Wiens M: Child development and long-term outcomes: a population health perspective and summary of successful interventions. Soc Sci Med 1996, 43(7):1083-1095.

5. Jacobs P, Dewa C, Lesage A, Vasiliadis H-M, Escober C, Mulvale G, Yim R: The Cost of Mental Health and Substance Abuse Services in Canada: A Report to the Mental Health Commission of Canada. In Alberta, Canada: Institute of Health Economics; 2010

6. Lim KL, Jacobs $\mathrm{P}$, Ohinmaa A, Schopflocher D, Dewa CS: A new populationbased measure of the economic burden of mental illness in Canada. Chronic Dis Can 2008, 28(3):92-98.

7. Petitclerc A, Tremblay RE: Childhood disruptive behaviour disorders: review of their origin, development, and prevention. Can J Psychiatry 2009, 54(4):222-231.

8. Cote SM, Boivin M, Liu X, Nagin DS, Zoccolillo M, Tremblay RE: Depression and anxiety symptoms: onset, developmental course and risk factors during early childhood. J Child Psychol Psychiatry 2009, 50(10):1201-1208.

9. Leblanc N, Boivin M, Dionne G, Brendgen M, Vitaro F, Tremblay RE, Perusse D: The development of hyperactive-impulsive behaviors during the preschool years: the predictive validity of parental assessments. J Abnorm Child Psychol 2008, 36(7):977-987.

10. Brezo J, Barker ED, Paris J, Hebert M, Vitaro F, Tremblay RE, Turecki G Childhood trajectories of anxiousness and disruptiveness as predictors of suicide attempts. Arch Pediatr Adolesc Med 2008, 162(11):1015-1021.

11. Brezo J, Paris J, Hebert M, Vitaro F, Tremblay R, Turecki G: Broad and narrow personality traits as markers of one-time and repeated suicide attempts: a population-based study. BMC Psychiatry 2008, 8:15.
12. Fontaine N, Carbonneau R, Barker ED, Vitaro F, Hebert M, Cote SM, Nagin DS, Zoccolillo M, Tremblay RE: Girls' hyperactivity and physical aggression during childhood and adjustment problems in early adulthood: a 15-year longitudinal study. Arch Gen Psychiatry 2008, 65(3):320-328.

13. Cote S, Zoccolillo M, Tremblay RE, Nagin D, Vitaro F: Predicting girls' conduct disorder in adolescence from childhood trajectories of disruptive behaviors. J Am Acad Child Adolesc Psychiatry 2001, 40(6):678-684.

14. Boivin M, Hertzman C (Eds): Early Childhood Development: Adverse Experiences and Developmental Health. Royal Society of Canada-Canadian Academy of Health Sciences Expert Panel (With Ronald Barr, Thomas Boyce, Alison Fleming, Harriet MacMillan, Candice Odgers, Marla Sokolowski, \& Nico Trocmé). Ottawa, ON: Royal Society of Canada; 2012.

15. Greenberg MT, Weissberg RP, O'Brien MU, Zins JE, Fredericks L, Resnik H, Elias MJ: Enhancing school-based prevention and youth development through coordinated social, emotional, and academic learning. Am Psychol 2003, 58(6-7):466-474.

16. World Health Organization: Prevention of Mental Disorders: Effective Interventions and Policy Options. Geneva, Switzerland: World Health Organization; 2004.

17. Luthar SS: Resilience and Vulnerability: Adaptation in the Context of Childhood Adversities. New York: Cambridge University Press; 2003.

18. Waddell C, McEwan K, Peters RD, Hua JM, Garland O: Preventing mental disorders in children: a public health priority. Can J Public Health 2007, 98(3):174-178.

19. Benzies KM, Harrison MJ, Magill-Evans J: Parenting stress, marital quality, and child behavior problems at age 7 years. Public Health Nurs 2004, 21(2):111-121

20. Benzies KM, Harrison MJ, Magill-Evans J: Parenting and childhood behavior problems: mothers' and fathers' voices. Issues Ment Health Nurs 2004, 25(1):9-24.

21. Letourneau N, Morris CY, Stewart M, Hughes J, Critchley KA, Secco L: Social support needs identified by mothers affected by intimate partner violence. J Interpers Violence 2013, 28(14):2873-2893.

22. Letourneau NL, Tramonte L, Willms JD: Maternal depression, family functioning and children's longitudinal development. J Pediatr Nurs 2013, 28(3):223-234

23. Tough SC, Johnston DW, Siever JE, Jorgenson G, Slocombe L, Lane C, Clarke M: Does supplementary prenatal nursing and home visitation support improve resource use in a universal health care system? A randomized controlled trial in Canada. Birth 2006, 33(3):183-194.

24. Tough SC, Siever JE, Leew S, Johnston DW, Benzies K, Clark D: Maternal mental health predicts risk of developmental problems at 3 years of age: follow up of a community based trial. BMC Pregnancy Childbirth 2008, 8:16.

25. Tough SC, Siever JE, Benzies K, Leew S, Johnston DW: Maternal well-being and its association to risk of developmental problems in children at school entry. BMC Pediatr 2010, 10:19.

26. Cardiff: TeleFrom. Release 10.1. Vista, CA: Cardiff; 2006

27. Statistics Canada: National Longitudinal Survey of Children and Youth (NLSCY). Ottawa: Statistics Canada; 2010

28. American Psychiatric Association: Diagnostic and Statistical Manual for Mental Disorders (DSM-IV-TR). Washington, DC: American Psychiatric Publishing; 2000

29. Hotton T: Childhood Aggression and Exposure to Violence in the Home Ottawa: Minister of Industry; 2003.

30. Glascoe FP: Collaborating With Parents: Using Parents' Evaluation of Developmental Status (PEDS) to Detect and Address Developmental and Behavioral Problems. Nashville, TN: Ellsworth \& Vandermeer; 2002.

31. Mah JK, Tough S, Fung T, Douglas-England K, Verhoef M: Parents' global rating of mental health correlates with SF-36 scores and health services satisfaction. Qual Life Res 2006, 15(8):1395-1401.

32. Trute B, Hiebert-Murphy D: Predicting family adjustment and parenting stress in childhood disability services using brief assessment tools. J Intellect Dev Dis 2005, 30(4):217-225

33. Strayhorn JM, Weidman CS: A parent practices scale and its relation to parent and child mental health. J Am Acad Child Adolesc Psychiatry 1988, 27(5):613-618.

34. Hosman C, Jané-Llopis E, Saxena S (Eds): Prevention of Mental Disorders: Effective Interventions and Policy Options. Oxford: Oxford University Press; 2005.

35. Achenbach TM, McConaughy SH, Howell CT: Child/adolescent behavioral and emotional problems: implications of cross-informant correlations for situational specificity. Psychol Bull 1987, 101(2):213-232. 
36. McGee R, Feehan M, Williams S: Long-Term Follow-up of a Birth Cohort. In The Epidemiology of Child and Adolescent Psychopathology. Edited by Verhulst FC, Koot HM. Oxford: Oxford University Press; 1995:366-384.

37. Buka SL, Stichick TL, Birdthistle I, Earls FJ: Youth exposure to violence: prevalence, risks, and consequences. Am J Orthopsychiatry 2001, 71(3):298-310.

38. Grant KE, Compas BE, Thurm AE, McMahon SD, Gipson PY: Stressors and child and adolescent psychopathology: measurement issues and prospective effects. J Clin Child Adolesc Psychol 2004, 33(2):412-425.

39. Conger RD, Conger KJ, Elder GH Jr, Lorenz FO, Simons RL, Whitbeck LB: A family process model of economic hardship and adjustment of early adolescent boys. Child Dev 1992, 63(3):526-541.

40. Luthar SS, Zigler E: Vulnerability and competence: a review of research on resilience in childhood. Am J Orthopsychiatry 1991, 61(1):6-22.

41. Luthar SS, Cicchetti D, Becker B: The construct of resilience: a critical evaluation and guidelines for future work. Child Dev 2000, 71(3):543-562.

42. Ttofi MM, Farrington DP: Risk and protective factors, longitudinal research, and bullying prevention. New Dir Youth Dev 2012, 2012(133):85-98.

43. Willis TA, Fegan MF: Social Networks and Social Support. In Handbook of Health Psychology. Edited by Baum A, Revenson T, Singer J. Mahwah, NJ: Lawrence Erlbaum Associates; 2001:209-234.

44. Jané-Llopis E, Barry MM: What makes mental health promotion effective. Glob Health Promot 2005, 12(2):suppl 47-suppl 54.

45. Brown H, Sturgeon S: Promoting a Health Start of Life and Reducing Early Risks. In Prevention of Mental Disorders: Effective Interventions and Policy Options. Edited by Hosman C, Jané-Llopis E, Saxena S. Oxford: Oxford University Press; 2005.

46. Pettit GS, Bates JE, Dodge KA: Supportive parenting, ecological context, and children's adjustment: a seven-year longitudinal study. Child Dev 1997, 68:908-923.

47. Herrenkohl TI, Klika JB, Brown EC, Herrenkohl RC, Leeb RT: Tests of the mitigating effects of caring and supportive relationships in the study of abusive disciplining over two generations. J Adolesc Health 2013, 53(4 Suppl):S18-S24.

48. Conger RD, Schofield TJ, Neppl TK, Merrick MT: Disrupting intergenerational continuity in harsh and abusive parenting: the importance of a nurturing relationship with a romantic partner. J Adolesc Health 2013, 53(4 Suppl):S11-S17.

49. Tough SC, Siever JE, Johnston DW: Retaining women in a prenatal care randomized controlled trial in Canada: implications for program planning. BMC Public Health 2007, 7:148

50. Young AF, Powers JR, Bell SL: Attrition in longitudinal studies: who do you lose? Aust N Z J Public Health 2006, 30(4):353-361.

51. Connell AM, Goodman SH: The association between psychopathology in fathers versus mothers and children's internalizing and externalizing behavior problems: a meta-analysis. Psychol Bull 2002, 128(5):746-773.

52. Wright JC, Zakriski AL, Drinkwater M: Developmental psychopathology and the reciprocal patterning of behavior and environment: distinctive situational and behavioral signatures of internalizing, externalizing, and mixed-syndrome children. J Consult Clin Psychol 1999, 67(1):95-107.

doi:10.1186/1471-2431-14-166

Cite this article as: Cabaj et al.: Early childhood risk and resilience factors for behavioural and emotional problems in middle childhood. BMC Pediatrics 2014 14:166.

\section{Submit your next manuscript to BioMed Central and take full advantage of:}

- Convenient online submission

- Thorough peer review

- No space constraints or color figure charges

- Immediate publication on acceptance

- Inclusion in PubMed, CAS, Scopus and Google Scholar

- Research which is freely available for redistribution

Submit your manuscript at www.biomedcentral.com/submit
C Biomed Central 